\title{
Global climate during Marine Isotope Stage 11 (MIS 11)
}

INQUA INTERNATIONAL WoRKSHOP, Lesvos, GREecE; 5-7 September 2005

The warm interval associated with Marine Isotope Stage 11 (MIS 11) approx. 400,000 years ago may be an appropriate analog for the natural progression of the Holocene interglacial climate. Atmospheric greenhouse gas concentrations were very similar to pre-industrial values, and the nearly circular orbit (low eccentricity) of the Earth at that time resulted in similar seasonal distributions of sunlight to today. The global climate response at that time is less well known, and a number of efforts are underway to improve our understanding of it. INQUA Project 0405 is focused on the goals of facilitating and coordinating research on MIS 11. A workshop was held to assess the current state of knowledge of various aspects of the chronology; external forcing by insolation and internal greenhouse-gas trapping of radiation; sea level height/ice volume; carbon cycle; and the mean state, regional patterns, and variability of the climatic and environmental responses during MIS 11.

The workshop was organized by Chronis Tzedakis at the University of the Aegean. Five key areas of research were identified:

1) climate forcing during MIS 11

2) absolute timing and duration of MIS 11

3) nature and magnitude of the climate response in different parts of the Earth system, including spatial and temporal patterns, and the presence of stability or instability

4) operation of the carbon cycle

5) integration of paleo-data with modelling studies

Presentations during the first day focused on paleodata from terrestrial, ice and marine archives. These included results from the EPICA Dome C ice core regarding the chronology of events, atmospheric greenhouse concentrations, the phasing between temperature, $\mathrm{CO}_{2}$ and $\mathrm{CH}_{4}$ changes, and compari-

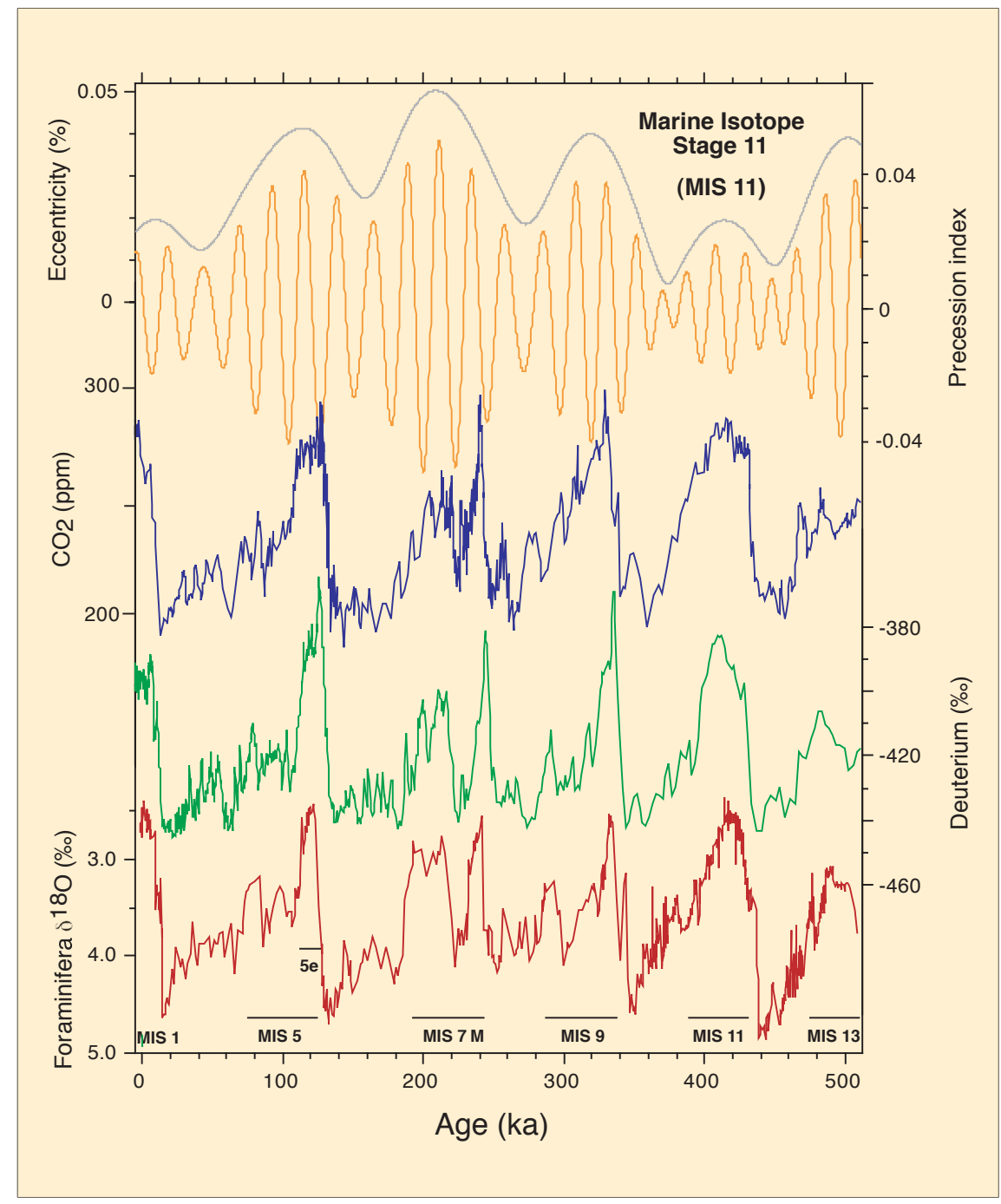

Fig. 1: Climate forcing and response over 0.5 million years. Eccentricity of Earth's orbit and precessional index (Berger and Loutre, 1991), atmospheric carbon-dioxide concentration (Petit et al., 1999; Monnin et al., 2001; Siegenthaler et al., 2005), deuterium ( $D$ D) in Antarctica (Wolff et al., 2003), and deep Atlantic benthic foraminifera oxygen isotope ratio (Oppo et al., 1998; McManus et al., 1999).

sons with the Holocene (Dominique Raynaud). They also included a discussion of evidence for sea levels $20 \pm 10 \mathrm{~m}$ higher than present, and possible explanations for the apparent discrepancy between coral/ shoreline and marine isotopic data (Jerry McManus). Additional presentations from marine archives included a demonstration of the scale of coral reef growth at the onset of MIS 11 (Andre Droxler) and a discussion of evidence for pronounced and prolonged marine carbonate dissolution from about 600 to 200 ka (Stephen Barker). A suite of proxies, indicating a long and stable interglacial interval in the
North Atlantic, was discussed and compared to widespread evidence for similar marine conditions (Jerry McManus), followed by a synthesis of research based on deep-sea cores from the Australian margin (Peter Kershaw). Terrestrial evidence was presented using marine pollen sequences from the Iberian margin that indicate the occurrence of one long interglacial interval followed by three shorter oscillations (Stephanie Desprat). A comparison of marine and terrestrial pollen records from southern Europe indicate that the most extensive tree population expansion during MIS 11 was coeval with both the insolation 


\title{
Workshop Reports
}

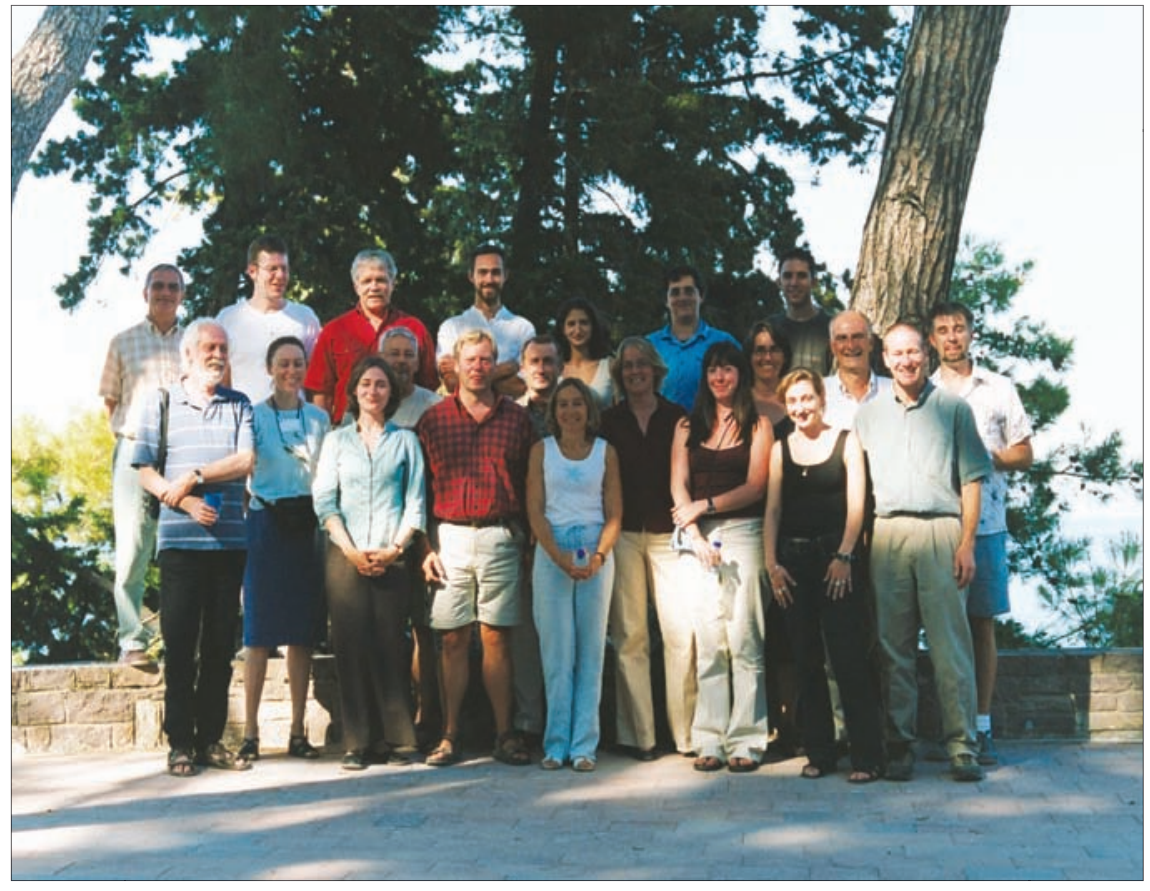

Fig. 2: Group photo of the MIS-11 workshop participants in Lesvos, Greece.

and atmospheric methane maxima (ChronisTzedakis), and some recent high resolution work was presented from annually laminated sediments from maar lakes in the Eifel region, Germany, which have the potential for constraining the duration of interglacial warmth (Frank Sirocko). New results were also presented from Lake Baikal, as was a synthesis of soil/loess sequences from China, Siberia and Russia (Sasha Prokopenko).

The second morning of the workshop was devoted to discussions of models, including the results of recent simulations for MIS 11 using the MoBidiC climate model that emphasized the importance of identifying appropriate vegetation inputs for the model (Marie-France Loutre). Climate simulations using the CLIMBER 2.3 model were presented, showing the pronounced geographical differences in the nature and timing of responses during MIS 11 (Claudia Kubatzki). Additional experiments using the CLIMBER model, indicating the terrestrial realm as a climate amplifier that had the potential to cause thresholds in the system to be crossed, were also presented and examined in the context of the global carbon cycle (Victor Brovkin). A new perspective on the entire problem of ice-age cycles was also presented, emphasizing the importance of putting the variability of the last few hundred thousand years in the context of a longer term view of climate evolution over the last few million years (Tom Crowley). The oral presentations of the workshop were followed by a poster session and a roundtable discussion of the arising scientific issues. The final day included presentations and discussion on the progress of the different study groups: Eurasian; Southern Hemisphere; Integration of marine, ice core and terrestrial records; Paleoclimate; and Carbon cycle. Progress was noted and gaps were identified in each of these areas.

The Lesvos workshop marked the mid-point of the INQUA inter-Congress period. Subsequent plans for the MIS 11 project include a workshop to be held at Woods Hole in 2006, and a symposium to be organized as part of the 17th INQUA Congress in Cairns, Australia in 2007.

\section{JeRRY McManus}

Woods Hole Oceanographic Institution, Woods Hole, USA

jmcmanus@whoi.edu

\section{Chronis Tzedakis}

University of Leeds, Leeds, UK P.C.Tzedakis@leeds.ac.uk

\section{Call for Contributions: General PAGES Activities}

\author{
All PAGES Newsletters now have an open section for general contributions. If you \\ would like to contribute a "Science Highlight", "Workshop Report", "Program \\ News", or an amusing "Tales from the field" story for the forthcoming July 2006 \\ issue of PAGES News, please contact Christoph Kull (kull@ pages.unibe.ch). \\ The deadline is 15 May 2006. \\ Information and guidelines are available at: \\ http://www.pages-igbp.org/products/contribute.html\#2
}

